Intravenous tissue-type plasminogen activator for treatment of acute stroke: the standard treatment with alteplase to Reverse Stroke (STARS) Study. JAMA 2000;283:1145-50.

3. Grond M, Stenzel C, Schmulling S, Rudolf J, Neveling M, Lechleuthner A, et al. Early intravenous thrombolysis for acute ischemic stroke in a community-based approach. Stroke 1998; 29:1544-99.

4. Adams HR Jr, Brott TG, Furlan AJ, Gomez CR, Grotta J, Helgason CM, et al. Guidelines for thrombolytic therapy for acute stroke: a supplement to the guidelines for the management of patients with acute ischemic stroke. Circulation 1996;94:1167-74.

5. Grotta J. Should thrombolytic therapy be the first-line treatment for acute ischemic stroke? TPA: the best current option for most patients. N Engl J Med 1997;337:1309-10.

6. Caplan LR, Mohr JP, Kistler JR, Koroshetz W. Thrombolysis: not a panacea for ischemic stroke. N Engl J Med 1997;337:1309-10.

7. Scott PA, Smith RW, Grant RJ, Chudnofsky CR, Fredriksen SM. Emergency physician administration of rtPA therapy in acute stroke: analysis of treatment and outcome [abstract]. Stroke 1999;30:244.

8. Tanne D, Bates VE, Verro P, Kasner SE, Binder JR, Patel SC, et al. Initial clinical experience with IV tPA for acute ischemic stroke: a multicenter study. Neurology 1999;53:424-7.

9. NINDS tPA Study Group. ICH after IV tPA for ischemic stroke. Stroke 1997;28:2109-18.

10. Lopez-Yunez AM, Bruno A, Zurru C. Protocol variations in community-based rtPA use are associated with symptomatic intracerebral hemorrhage [abstract]. Stroke 1999;30:264.

11. del Zoppo GJ. Thrombolytic therapy in the treatment of stroke [discussion]. Drugs 1997;54 Suppl 3:90-8.

12. Tong DC, Yenari MA, Albers GW. Intravenous thrombolytic therapy in acute stroke. Vasc Med 1997;2:51-60.

13. Mohr JP. Thrombolytic therapy for ischemic stroke [editorial]. JAMA 2000;283:1189-91.

Correspondence to: Dr. David Rhine, PO Box 3354, MBC 84, Riyadh 11211, Saudi Arabia; drhine@ @otmail.com

\title{
Amiodarone for out-of-hospital cardiac arrest
}

\section{Clinical question}

Does intravenous amiodarone improve outcomes in patients with out-of-hospital cardiac arrest due to shockrefractory ventricular fibrillation (VF) or tachycardia (VT)?

\section{Article chosen}

Kudenchuk PJ, Cobb LA, Copass MK, Cummins RO, Doherty AM, Fahrenbruch CE, et al. Amiodarone for resuscitation after out-of-hospital cardiac arrest due to shockrefractory ventricular fibrillation or tachycardia. N Engl J Med 1999;341:871-8.

\section{Objective}

To determine, in out-of-hospital cardiac arrest patients with refractory VF or VT, whether intravenous amiodarone, given within a standard ACLS (advanced cardiac life support) protocol following a minimum of 3 shocks, increases survival to hospital with a perfusing rhythm.

\section{Background}

There are more than 250,000 cardiac deaths annually in the US, many due to ventricular fibrillation. ACLS guidelines state that antiarrhythmic medications are "acceptable and probably helpful" for patients with VF or pulseless VT persisting after 3 or more shocks. ${ }^{1}$ However, to date, there is little supporting evidence for this statement.

\section{Population studied}

Victims of non-traumatic, out-of-hospital cardiac arrest in a
Reviewers: Michael J Bullard, MD; Joseph Vipond, MD University of Alberta, Edmonton, Alta.

Date appraised: April 2000

Received: May 5, 2000; accepted: May 10, 2000.

city served by well trained emergency medical services (EMS) providers, including emergency medical technician (EMT)-defibrillation first responders and paramedics dispatched simultaneously for life-threatening calls.

\section{Study design}

This was a double-blind randomized clinical trial of singledose intravenous amiodarone $(300 \mathrm{mg})$ versus its diluent, polysorbate 80 , as placebo. Eligible patients were those with persistent VF or pulseless VT following 3 or more precordial shocks, intubation and intravenous epinephrine $(1 \mathrm{mg})$. All other resuscitative efforts were based on existing standard protocols. Data were collected from dispatch records, EMS records, ECG and defibrillator recorders, hospital records, and survivors or their family members.

\section{Outcomes measured}

The primary end point was admission to hospital with a spontaneously perfusing rhythm. Secondary end points were adverse effects, number of precordial shocks required after study drug administration, duration of resuscitative efforts, and the need for additional antiarrhythmics. Survival to discharge and functional neurological status at 
discharge were documented but not considered as end points due to insufficient study power.

\section{Results}

During the study period, 507 of 667 eligible patients were enrolled, 246 in the amiodarone group and 258 in the placebo group. Clinical characteristics of "included" and "excluded" patients were similar, but minor differences were reported between amiodarone and placebo recipients. More witnessed arrests occured in the placebo group (77\% vs. $70 \%$ ), and bystander CPR was more common in the amiodarone group (68\% vs. 59\%).

With respect to the primary outcome, amiodarone was associated with increased survival to hospital admission (44\% vs. $34 \%, p<0.03$ ); however, more amiodarone patients required inotropic support $(59 \%$ vs. $48 \%, p=$ 0.04 ), and more amiodarone recipients developed bradycardia $(41 \%$ vs. $25 \%, p=0.004)$ and hypotension (mean systolic BP, $104+/-41$ vs. $117+/-36, p=0.04)$. Women were more likely to benefit from amiodarone than men (adjusted odds ratio for survival to hospital, 4.3 vs. 1.2). There was no difference between amiodarone and placebo in survival to hospital discharge (13.4\% vs. $13.2 \%)$.

\section{Study conclusions}

The addition of amiodarone to prehospital advanced cardiac life-support measures resulted in greater survival rates to hospital $(\mathrm{NNT}=10)$. There was no difference between the groups in discharge from the hospital, although the study was not powered to examine this outcome.

\section{Commentary}

New ACLS guidelines will be published this fall, and "reliable sources" say that amiodarone will be recommended as the first-line antiarrhythmic for refractory out-of-hospital ventricular tachydysrhythmias. This despite the fact that convincing evidence of survival benefit exists for only 2 interventions - timely precordial shocks and early CPR.,

The authors of this study conclude that in patients with VF or VT unresponsive to 3 defibrillations, amiodarone treatment generates one more survivor (to hospital) for every 10 patients treated. They acknowledge that the study was too small to compare survival to discharge, but it is worrisome that there was not even a trend toward improvement in the amiodarone group. As Ballew and Philbrick ${ }^{4}$ point out, survival to hospital but not to hospital discharge would increase medical care costs without improving overall mortality.

Few trials have shown a significant survival benefit for amiodarone over placebo, ${ }^{5}$ but a recent meta-analysis concluded that in high-risk patients with recent myocardial infarction or congestive heart failure, amiodarone treatment prevents arrhythmic sudden death and leads to a $13 \%$ reduction in overall mortality. ${ }^{6}$

In a recent Canadian trial comparing amiodarone to implantable cardioverter defibrillators (ICD), ICD therapy was associated with a $20 \%$ decrease in all-cause mortality and a 33\% reduction in arrhythmic death, although these differences did not achieve statistical significance. ${ }^{7}$ The data described above suggest that, given a choice, electricity is preferable and remains the treatment of choice.

Not long ago, we administered lidocaine to patients with suspected acute myocardial infarction and "high risk" premature ventricular contractions. Only later did we learn that this practice caused more harm than good. ${ }^{8}$ Future studies will clarify whether or not amiodarone improves meaningful survival. Until this evidence appears, it seems premature to recommend amiodarone for all patients with refractory VF/VT cardiac arrest. Health care costs are an important concern, and the cost of equipping every advanced life support ambulance in the developed world with amiodarone will be more than substantial.

\section{References}

1. Commins RO, editor. Textbook of advanced cardiac life support. Dallas: American Heart Association; 1997. p. 1-17.

2. Eisenberg MS, Horwood BT, Cummins RO, Reynolds-Haertle R, Hearne TR. Cardiac arrest and resuscitation: a tale of 29 cities. Ann Emerg Med 1990;19:179-86.

3. Cobb LA, Werner JA, Trobaugh GB. Sudden cardiac death. I: A decade's experience with out-of-hospital resuscitation. Mod Concepts Cardiovasc Dis 1980;49:31-6.

4. Ballew KA, Philbrick JT. Amiodarone in out-of-hospital cardiac arrest. N Engl J Med 2000;342:216-7.

5. Julian DG, Camm AJ, Frangin G, Janse MJ, Munoz A, Schwartz $\mathrm{PJ}$, et al. Randomised trial of effect of amiodarone on mortality in patients with left-ventricular dysfunction after recent myocardial infarction: EMIAT. European Myocardial Infarct Amiodarone Trial Investigators. Lancet 1997;349:667-74.

6. AmiodaroneTrials Meta-Analysis Investigators. Effect of prophylactic amiodarone on mortality after acute myocardial infarction and in congestive heart failure: meta-analysis of individual data from 6500 patients in randomised trials. Lancet 1997;350:1417-24.

7. Connolly SJ, Gent M, Roberts RS, Dorian P, Roy D, Sheldon RS, et al. Canadian implantable defibrillator study (CIDS): a randomized trial of the implantable cardioverter defibrillator against amiodarone. Circulation 2000;101:1297-302.

8. Hine LK, Laird N, Hewitt P, Chalmers TC. Meta-analytic evidence against prophylactic use of lidocaine in acute myocardial infarction. Arch Intern Med 1989;149:2694-8.

Correspondence to: michael.bullard@ualberta.ca 


\section{CJEM ${ }_{\mathrm{E}^{\mathrm{B}} \mathrm{J}}^{\mathrm{J}} \mathrm{JCMU}$}

\section{The official journal of the Canadian Association of Emergency Physicians}

\section{SUBSCRIPTION ORDER FORM}

Mail to: Canadian Association of Emergency Physicians

1785 Alta Vista Dr., Ste. 104

Ottawa ON K1G 3 Y6

Fax to: 613 523-0190

Name

Address

Address

City, Province

Postal Code

Phone

Fax

Price: Canada \$50 per year (four issues). United States and elsewhere, US\$50.

Method of payment:

Cheque enclosed ( )

Visa card no:

Expiry date

MasterCard no:

Expiry date

Please send me information on CAEP membership ( ) 